\title{
Nicolás Sánchez Albornoz (2014). Historia mínima de la población de América Latina. Cuatrocientos siglos de historia, desde los tiempos precolombinos hasta el (no tan lejano) año 2025. Madrid, España: Editorial Turner
}

\author{
Fabián Bustamante Olguín* \\ Área de Humanidades, Facultad de Ciencias Físicas y Matemáticas, \\ Universidad de Chile, Santiago, Chile
}

Este libro, del reconocido historiador español Nicolás Sánchez Albornoz, inserta en una mínima colección editada por El Colegio de México, es la versión actualizada de la primera edición de la obra, publicada bajo el título La población de América Latina. Desde los tiempos precolombinos hasta el año 2000. Esa primera edición data de 1973, por Alianza Editorial, en Madrid, la cual a su vez fue el resultado de una temprana publicación de 1968 -junto a José Luis Moreno-, titulada La población de América Latina: bosquejo histórico, publicada en Buenos Aires, Argentina.

Estamos, por tanto, en presencia de una obra monumental que es, sin lugar a dudas, el resultado de largos años de investigación sobre demografía histórica de América Latina. Sobre este último punto es necesario destacar que gran parte de las fuentes se debe a investigaciones realizadas por demógrafos, más no por historiadores.

Se podría decir, en términos generales, que el libro -en sus 285 páginas- contiene una síntesis que aborda los cambios demográficos ocurridos desde los pueblos precolombinos hasta sus proyecciones hacia el año 2025. Estas últimas corresponden a un apartado nuevo, ausente en la edición de Alianza. Con una incansable rigurosidad, el profesor Sánchez Albornoz trabaja el cambio de la población latinoamericana sobre la base de variables básicas tales como fertilidad, mortalidad, distribución y migración. Esto, por cierto, hace de este libro un material de consulta obligada para todo historiador latinoamericano.

Historiador. Magíster en Historia, Universidad de Santiago de Chile. Profesor del Área de Humanidades, Facultad de Ciencias Físicas y Matemáticas de la Universidad de Chile, y de la Escuela de Sociología, Universidad Católica Silva Henríquez. Correo electrónico: fgbustamanteo@gmail.com 
El libro contiene nueve capítulos -que incluyen cuadros y gráficos estadísticos-, divididos en torno a dos grandes períodos que presentan la evolución histórica del cambio demográfico latinoamericano, a saber: el primer período abarca desde la llegada de los primeros cazadores que cruzaron el estrecho de Bering hasta la Conquista, y el segundo período comprende desde el siglo XV hasta el presente (y el no muy lejano 2025).

En el primer capítulo ("Bosquejo y fuentes"), el autor comenta que las fuentes utilizadas para desarrollar esta obra provienen de la paleodemografía o demografía antropológica, censos, padrones o matrículas, por un lado, y de registros civiles o parroquiales, por otro. Con todo -sostiene Sánchez Albornoz-, en la estadística demográfica de América Latina existen tres etapas de complejidad y regularidad crecientes. La primera de éstas es el período preestadístico (1514-1775), que abarca desde el primer repartimiento de indios hasta el primer censo general realizado en la región, de 1775, caracterizado por un tipo de fuente asociada a matrículas de tributarios y libros parroquiales. La segunda etapa corresponde al período protoestadístico (1775-1880), que se inicia por la preocupación de España y Portugal de censar sus posesiones de ultramar, recayendo la labor estadística en manos de las autoridades civiles o religiosas, para luego, en el período de independencia, recaer en la administración pública, la cual que asumió paulatinamente la recopilación demográfica. Desde ya, los Estados crearon organismos para reunir información estadística, siendo los censos y registros civiles las principales modalidades de obtención de información. Por último, el período estadístico (1880- hasta hoy) durante el cual los censos y registros se comenzaron a realizar con regularidad en la mayoría de las naciones latinoamericanas.

Así, entonces, el autor realiza un extenso recorrido (como aparece en el capítulo dos, "El poblamiento aborigen") a partir de las primeras oleadas de inmigrantes de pueblos cazadores venidos desde Asia a América, hace unos 40.000 años. A partir de ahí, Sánchez Albornoz sostiene una interesante tesis según la cual América, por casi 400 siglos, fue una prolongación étnica de Asia. Algunos de esos primeros habitantes consiguieron asentarse en diversos lugares del continente, dando nacimiento a los primeros pueblos y ciudades. Ciudades que, por cierto, con el paso del tiempo tuvieron una avanzada arquitectura para el caso de los grandes imperios (Tenochtitlán y Cuzco), surgidos previo a la llegada de los españoles, como fue el caso azteca, maya o inca.

Sin embargo, el período de la Conquista de América en adelante (desarrollado en el capítulo tres, "Derrumbe de la población indígena" y en el capítulo cuatro, "La implantación europea y africana") constituye un punto central del planteamiento del autor. En ese sentido, Sánchez Albornoz sostiene la tesis según la cual desde los siglos XVI y XVII 
habría existido un período de contracción evidente en América Latina producto de los efectos del colonialismo español, donde la mortalidad de los pueblos indígenas, sobre todo en el área del Caribe, mermó por completo a la población. La violencia genocida española, sumada a las enfermedades traídas desde Europa, fueron las variables de la debacle de la población aborigen. Esta cuestión tuvo como efecto la implantación de población africana para reemplazar en ciertas áreas a la población local, en tanto que manos de obra para la extracción de materias primas.

Durante la segunda mitad del siglo XVII en adelante (explica el autor en el capítulo cinco, "El nuevo derrotero"), la población latinoamericana repunta cuantitativamente, igualando en volumen al período anterior a la Conquista, gracias al aporte de europeos, africanos y asiáticos. Sin embargo, este período histórico -como sostiene el autor- fue complejo, de altos y bajos, debido a dos factores. El primero de ellos es que, a pesar del mencionado aporte foráneo a la población latinoamericana, ello no estuvo exento de algunas bajas de población producto de las enfermedades -arriba señaladas- como el sarampión, la peste bubónica y otras miles de enfermedades traídas del Viejo Mundo. El otro factor fue que en el último tercio del siglo XVIII existió un alza más regular de población lo que, en consecuencia, permitió el crecimiento sosegado de las primeras ciudades importantes del continente.

Tal crecimiento, por su parte, tuvo una explosión durante el siglo XIX (capítulo seis, "Gobernar es poblar") con la inmigración en masa de millones de europeos que llegaron principalmente a Brasil, Argentina y Uruguay. Demás está decir que esta inmigración fue fomentada por el ideologismo decimonónico de tinte racista que consideraba que la llegada de población blanca posibilitaría el progreso de nuestros países. Todo ello, por cierto, amparado en una serie de leyes protectoras para fomentar este aluvión migratorio.

Agréguese a lo anterior que el interés de las elites era en un comienzo la llegada de inmigrantes de Europa del norte (en lo posible blanco, nórdico y católico), quienes prefirieron embarcarse hacia Estados Unidos. Sin embargo, el espacio fue ocupado por la masiva llegada de europeos del sur (italianos, españoles y portugueses), quienes llegaron en búsqueda de mejores oportunidades para prosperar y escalar socialmente.

Cabe señalar que tal inmigración en masa, ocurrida entre los años 1870 a 1930 -señala Sánchez Albornoz-, implicó el arribo de cerca de 13 millones de europeos a América Latina. Arribo que, en efecto, disminuyó con el correr del tiempo debido a que algunos de ellos decidieron volver a sus países de origen por diversas razones. Ello no fue óbice para la aceleración considerable de población en países como Argentina, Brasil, Uruguay -que 
vieron marcada su nación para siempre con el aporte europeo-, y en menor medida, Chile, Cuba y Venezuela.

En los capítulos siete ("La explosión demográfica”), ocho ("Del terruño a la metrópoli”) y nueve ("El año 2025”), el autor va dibujando su tesis en torno a que América Latina ha tenido un crecimiento explosivo, al punto de que hacia el año 2025 se convertirá en el tercer continente con mayor población en el mundo, detrás de Asia y África, con 777 millones de habitantes.

Es interesante, por otro lado, el dato que nos proporciona el autor referido al crecimiento de las ciudades en nuestro continente. Al respecto, Sánchez Albornoz sostiene que 4 de las 10 urbes más grandes del mundo estarían en América Latina. Tal será el caso de Ciudad de México, con unos 30 millones de habitantes, Sao Paulo, 18 millones y Buenos Aires con 14 millones.

En relación a lo anterior, hay que destacar que tal aumento tuvo su punto de partida entre 1955 y 1965, cuando se estima que nuestro continente creció unos 6 millones de habitantes por año, destacándose países como Brasil y Venezuela. Esta explosión, en efecto, se debió a un desajuste en las variables de mortalidad y fecundidad. Tal desajuste se vio expresado en la reducción de la mortalidad y en el aumento, claro está, de la fecundidad. Otro elemento no menos importante para esta explosión -explicada por Sánchez Albornoztiene relación con el descenso brusco de las enfermedades infecciosas, gracias a la introducción de nuevas técnicas para combatirlas.

También se destaca que la alta fecundidad del período señalado fue producto de la promoción de las concepciones natalistas difundidas tanto por la Iglesia católica (por principios) como por el Estado (por cuestiones políticas, económicas y militares). Por cierto, los únicos países latinoamericanos donde operó una gran reducción demográfica fue Cuba (por las prácticas anticonceptivas promocionadas a partir de 1959 con la Revolución Cubana) y Puerto Rico (por el efecto combinado de la emigración, del incremento del nivel de vida e de intensas campañas de planificación familiar y de esterilización).

Como se dijo más arriba, la referida explosión demográfica tuvo como resultado un sobrante de población, lo cual provocó -además- el éxodo rural hacia las principales ciudades capitales de América Latina, así como también la partida hacia países colindantes de la región (Argentina, por ejemplo), y a Estados Unidos, Europa, Medio Oriente y Asia. 
En resumen, estamos ante un libro rector para los programas de estudios sobre América Latina, que aporta una gran cantidad de datos estadísticos, que sólo Nicolás Sánchez Albornoz, en su larga trayectoria, con una innumerable bibliografía acerca de este tema, nos permite conocer minuciosamente el estudio de la población latinoamericana. 